\title{
How the ascorbic acid and hesperidin do improve the biological activities of the cinnamon: theoretical investigation
}

\author{
Bachir Zouchoune ${ }^{1,2}$ (D)
}

Received: 28 May 2020 / Accepted: 10 July 2020 / Published online: 15 July 2020

(C) Springer Science+Business Media, LLC, part of Springer Nature 2020

\begin{abstract}
DFT/B3LYP calculations have been performed on series of molecules of natural products containing cinnamon and citrus, namely, cinnamic aldehyd, ascorbic acid and hesperidin. This theoretical investigation predicts the biological activities of mixtures between cinnamon and ascorbic acid and between cinnamon and hesperidin based on already proven values for these molecules. The strength of the intermolecular interactions is evaluated in term of energy decomposition of the total interaction energy $\Delta E_{\text {int }}$ between molecules, which are mainly governed by electrostatic interactions. The HOMO-LUMO gaps explain that the possible charge transfer interactions that take place within the molecules are responsible for the molecular reactivity of the studied molecules. The chemical hardness, the chemical potential and the electrophilicity indexes are good indicators for biological activities showing their improvement to that of cinnamon itself. The mixture of hesperidin and cinnamon could be an excellent blood thinner with the regard to its polarity's enhancement.
\end{abstract}

Keywords DFT calculations $\cdot$ Energy decomposition analysis $\cdot$ Hydrogen bond interactions $\cdot$ Biological activities

\section{Introduction}

Human body necessitates a good immunity to fight and resist against viruses; in fact, a vitamin-rich diet is highly recommended daily. Vitamins with important biological properties contained in natural products are countless, particularly in vegetables and fruits. Among these products are the cinnamon, vitamin $\mathrm{C}$ and hesperidin, which are much known for their benefits. The cinnamon is known for its many virtues, where most important portion of the essential oil is composed of cinnamic aldehyde [1]. This latter is responsible for the taste and odour of cinnamon. Cinnamon has been used as medicine around the world because of its health advantages.

Cinnamic adehyde is an active compound isolated from the stem bark of cinnamon, an oriental herb. The cinnamic

Bachir Zouchoune

bzouchoune@gmail.com

1 Unité de Recherche de Chimie de l'Environnement et Moléculaire Structurale, Université de Constantine (Mentouri),

25000 Constantine, Algeria

2 Laboratoire de Chimie Appliquée et Technologie des Matériaux, Université Larbi Ben M'hidi Oum el Bouaghi, 04000 Oum El Bouaghi, Algeria aldehyde has been shown to possess antihyperglycemic activity in diabetic rats $[2,3]$ an inhibition property of tumour cell propagation $[4,5]$, antioxidative [6] and anti-inflammatory activities [7]. Cinnamic aldehyde dimerization has been reported to hinder tumour cell development [8].

Antiviral activity of cinnamon bark was revealed to be efficient against influenza virus [9]. Antiviral drugs propose the principal line of defence for virus pandemic, when vaccines are not available in time [10].

Otherwise, several works suggested that vitamin $\mathrm{C}$ is capable to play a crucial role in the treatment against viral infections, particularly in high concentrations is directly virucidal [11]. Recently, experimental investigations demonstrated a beneficial effect of vitamin $\mathrm{C}$ in viral infections $[12,13]$.

The hesperidin (flavanone) is a major flavonoid located particularly in the membrane and peel of citrus. Hesperidin reveals numerous pharmacological effects like as antihyperlipidemic, cardioprotective, antihypertensive and antidiabetic activities, which are mainly attributed to an antioxidant defence mechanism and suppression of proinflammatory cytokine production [14-16].

The object of this work is to predict the impact of vitamin C (ascorbic acid) and hesperidin on the biological activities of cinnamon using DFT/B3LYP calculations (See "Computational methods") by evaluating the intermolecular 
hydrogen bonding and energy decomposition. In order to predict biological activities, chemical hardness [17, 18], chemical potential and electrophilicity indexes [19] are calculated, which are global reactivity descriptors, with high performance in predicting global chemical reactivity trends. The electrophilicity is a significant index of reactivity permitting a quantitative classification of the electrophilic nature of a molecule [19] and presented as a measure of favourable change in energy upon saturation of a system with electrons.

\section{Computational methods}

Density functional theory (DFT) calculations were carried out on the studied molecules using the Amsterdam Density Functional (ADF) program, version 2016.01 [20] developed by Baerends and co-workers [21-25]. All geometries discussed in this study have been optimized at the hybridtype B3LYP functional (Becke's three parameter hybrid exchange functional coupled with the Lee-Yang-Parr non-local correlation functional) $[26,27]$ employing the associated parameterization of Vosko-Wilk-Nusair [28], which treats the electron correlation. The numerical integration procedure applied for the calculations was developed by te Velde et al. [25] The atom electronic configurations were described by a triplez Slater-type orbital (STO) basis set for H 1s, C 2s and 2p, O $2 \mathrm{~s}$ and $2 \mathrm{p}$ augmented with a $3 \mathrm{~d}$ single- $\zeta$ polarization for $\mathrm{C}$ and $\mathrm{O}$ atoms and with a $2 \mathrm{p}$ single- $\zeta$ polarization for $\mathrm{H}$ atoms. Full geometry optimizations were carried out using the analytical gradient method implemented by Versluis and Ziegler [29]. Frequency calculations $[30,31]$ were performed on all the studied molecules of singlet spin state to check that the optimized structures are at local minima on the potential energy surface. Representation of the molecular orbitals and molecular structures was done using ADF-GUI [20]. The intermolecular bonding in the investigated molecules was analysed within the Morokuma-Ziegler EDA analysis [32, 33]. This analysis allows to explore the nature of the interaction between the molecules through the decomposition of the total bonding energy (TBE) in different terms: $\Delta E_{\text {int }}=\Delta E_{\text {pauli }}+\Delta E_{\text {elstat }}+$ $\Delta E_{\text {orb }}$ These three energetic components describe the Pauli repulsion, electrostatic interaction and orbital interaction, respectively, [33] using the NBO 6.0 program [34, 35]. Interaction energies have been corrected from basis set superposition error (BSSE) with the counterpoise method developed by Boys and Bernardi [36].

\section{Molecular structures}

Full geometry optimizations have been carried out on cinnamic aldehyde, ascorbic acid and hesperidin (Fig. 1). The cinnamic aldehyde was revealed to be a planar molecule due to the conjugation of the $\pi$-electron system.

The molecular structure shows an average bond distance of $1.396 \AA$ within the phenyl ring suggesting a bond order of 1.5 corresponding to a delocalized scheme of $\pi$-electrons as found previously for polycyclic hydrocarbons [37, 38]. The $\mathrm{C}_{2} \mathrm{H}_{2} \mathrm{COH}$ aldehyde group attached to the phenyl ring shows the existence of $\mathrm{C}(2)-\mathrm{C}(3)$ double bond of $1.350 \AA$ and a $\mathrm{C}(1)-\mathrm{C}(2)$ single bond of $1.475 \AA$. The aldehyde group is attached to the phenyl through $\mathrm{C}(3)-\mathrm{C}(4)$ single bond of $1.459 \AA$. The cinnamic aldehyde molecule exhibits a large HOMO-LUMO gap of $4.371 \mathrm{eV}$ where the HOMO-1 is localized on whole molecule except the $\mathrm{C}(1)$ atom exhibiting a bonding character which could play an electron donor role (Fig. 2); however the LUMO is mainly localized on entire molecule with slightly antibonding character, which could play an electron acceptor role. The ascorbic acid is described by a distorted structure characterized by dihedral angles deviating from the planarity. The $\mathrm{C} 4 \mathrm{O}$ five-member ring is described by a localized scheme corresponding to one $\mathrm{C}(4)$ $\mathrm{C}(5)$ double bond of $1.338 \AA$ and two single bonds $\mathrm{C}(3)$ $\mathrm{C}(4)$ and $\mathrm{C}(5)-\mathrm{C}(6)$ of 1.514 and $1.462 \AA$, respectively, besides the two $\mathrm{C}(3)-\mathrm{O}(6)$ and $\mathrm{C}(6)-\mathrm{O}(6)$ single bonds of 1.455 and $1.381 \AA$, respectively. The $\mathrm{O}-\mathrm{H}$ bond distances are about $0.97 \AA$. The $\mathrm{C}-\mathrm{O}-\mathrm{H}$ angles are in the range $106-109^{\circ}$ comparable with those of $\mathrm{H}-\mathrm{O}-\mathrm{H}$ in water molecule. The optimized structure displays a large HOMO-LUMO gap of $4.992 \mathrm{eV}$.

The HOMO is exclusively localized on $\mathrm{C}(4)-\mathrm{C}(5)$ bond of the five-member ring with a bonding $\pi$ character and on the oxygen atoms attached to this ring displaying $\pi^{*} \mathrm{C}-\mathrm{O}$ antibonding characters. Whereas, the hespridin is distorted molecule displaying a delocalized scheme within the sixmember $\mathrm{C} 6$ cycles 1 and 3, in relationship with the average bond distance of $1.395 \AA$ corresponding to bond order of 1.5 comparable to that computed for polycyclic aromatic ligands [39-42]. The $\mathrm{COH}$ angles are bent in the range $105-110^{\circ}$. The six-member $\mathrm{C} 5 \mathrm{O}$ cycles 2,4 and 5 are strongly distorted with carbon atoms in $\mathrm{sp}^{3}$ hybridization and long $\mathrm{C}-\mathrm{C}$ and $\mathrm{C}-\mathrm{O}$ bond lengths in the range 1.510 $1560 \AA$ and $1.390-1.430 \AA$, respectively. The hespridin exhibits large HOMO-LUMO gap of $4.56 \mathrm{eV}$, where the three highest molecular orbitals (HOMO-2, HOMO-1, HOMO) are mainly localized on the six-member $\mathrm{C} 6$ ring with $\pi \mathrm{C}-\mathrm{C}$ bonding character and non-negligible contributions of the lone electron pair of oxygen atoms. This electron localization allows to the flavanone part to play an electron donor role and to interact preferentially with other molecules. Also, the three lowest unoccupied molecular orbitals (LUMO, LUMO+1, LUMO+2) are principally localized on one six-member $\mathrm{C} 6$ ring with an antibonding $\pi^{*} \mathrm{C}-\mathrm{C}$ character giving rise to these orbitals to be an electron acceptors. 
Fig. 1 Lowest optimized structures of cinnamic aldehyde (a), ascorbic acid (b) and hesperidin (c) molecules

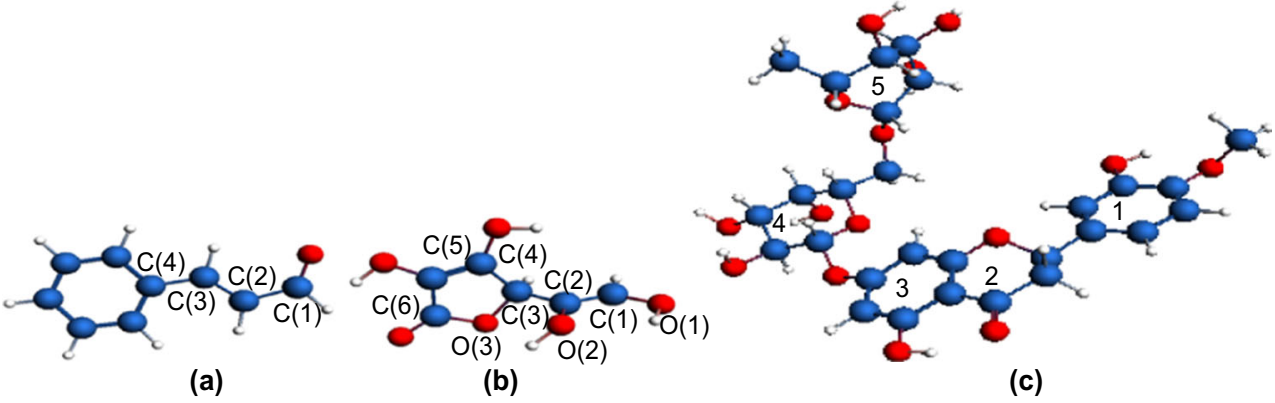

(a) (c)
The intermolecular interactions for the ascorbic acid (1), the cinnamic aldehyd (2) and hesperidin dimer (3) as dimers and for the mixture complexes between ascorbic acid and hesperidin (4), cinnamic aldehyd and ascorbic acid (5) and cinnamic aldehyd and hesperidin (6) are evaluated on the basis of the hydrogen bonds, which are specific, short-range, and directional nonbonded interactions. They occur between a hydrogen atom bound covalently to an electronegative atom like as $\mathrm{O}$ and another electronegative atom of the same or different nature (oxygen or carbon for the studied molecules). The distances of 2.5-3.2 $\AA$ between hydrogen-bond donor $\mathrm{X}$ and $\mathrm{Y}$ and $\mathrm{X}-\mathrm{H} \cdots \mathrm{Y}$ angles of $130-180^{\circ}$ are typically found [43].
The bond angle formed by the three concerned atoms is important in determining the strength of the hydrogen bond $\mathrm{X}-\mathrm{H} \cdots \mathrm{Y}$. Their strength is most favourable when the bond angle is near to the linearity (about $180^{\circ}$ ) and the $\mathrm{H}$ donor tends to point towards the acceptor electron pair. It is the case for the interactions occurred between cinnamic aldehyde and ascorbic acid displaying angles of $161^{\circ}$ and $164^{\circ}$ for the $\mathrm{O}-$ $\mathrm{H} \cdots \mathrm{O}$ and $\mathrm{C}-\mathrm{H} \cdots \mathrm{O}$ interactions, respectively, while the angles obtained for the intermolecular interactions between cinnamic aldehyde molecules are much open of $147^{\circ}$ and $149^{\circ}$, considered less strength than those occurred in case (5). The values of these angles are in accordance with the
Fig. 2 Frontier molecular orbitals for cinnamic aldehyd (a), ascorbic acid (b) and hesperidin (c)
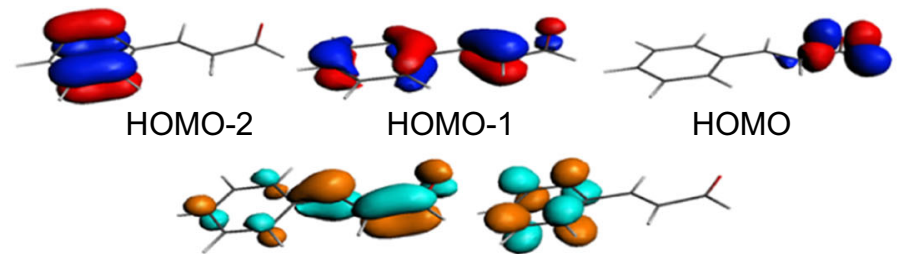

LUMO

(a)
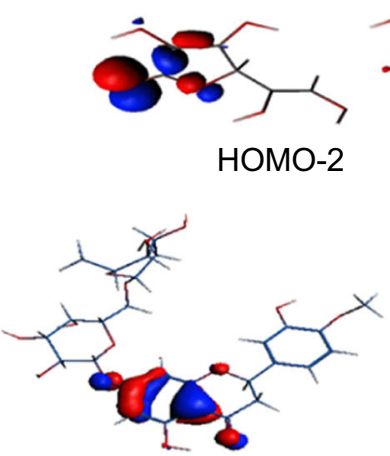

HOMO-2

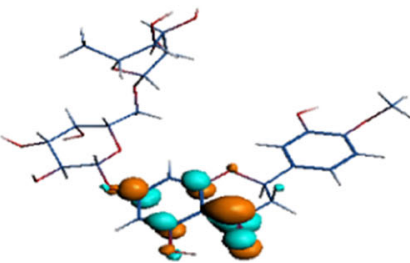

LUMO
HOMO-2

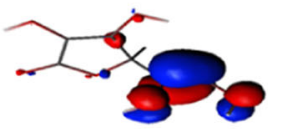

HOMO-1

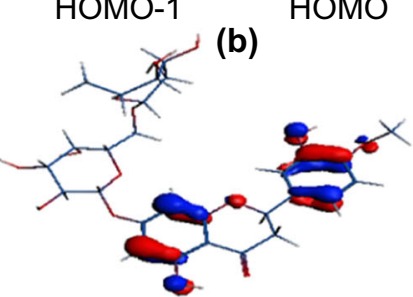

HOMO-1

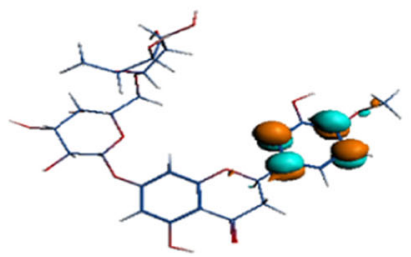

$\mathrm{LUMO}+1$

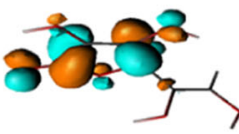

LUMO

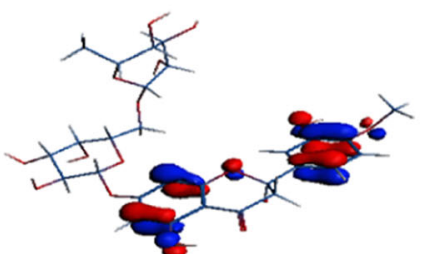

HOMO (c)

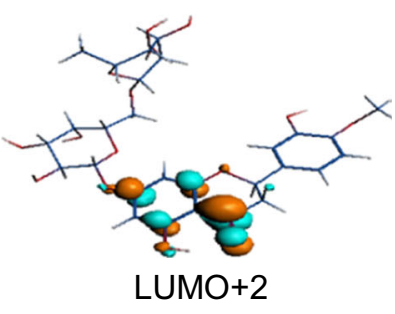

LUMO+2 
distance between $\mathrm{H}$ donor atom and the acceptor oxygen atom.

The intermolecular interactions between the cinnamic aldehyde monomers gave rise to the aldehyde functions face to face in the dimer, where the optimization gave the $\mathrm{O}-\mathrm{H}$ bond distance of $0.971 \AA$ and two hydrogen bonding interactions $\mathrm{O}-\mathrm{H} \cdots \mathrm{O}$ of 2.535 and $2.580 \AA$. While, the intermolecular interactions between cinnamic aldehyde and ascorbic acid are characterized by two $\mathrm{O}-\mathrm{H} \cdots \mathrm{O}$ of 1.798 and $2.830 \AA$ and one $\mathrm{C}-\mathrm{H} \cdots \mathrm{O}$ of $2.980 \AA$ (Fig. 3).

The most noticeable variation is a lengthening of the $\mathrm{O}(1)$ $\mathrm{H}$ and $\mathrm{O}(2)-\mathrm{H}$ bonds of the ascorbic acid, which are directly involved in the intermolecular interactions. It amounts to $0.03 \AA$ when one goes from the ascorbic acid molecule to model (5).

The intermolecular $\mathrm{O}-\mathrm{H} \cdots \mathrm{O}$ hydrogen bond that occurs in case (5) has been found to be strengthened in this way.

The intermolecular interactions between the ascorbic acid monomers consist of two hydrogen bonding of short distances of 1.877 and $1.897 \AA$, which give strong interactions in the dimer compared with those between cinnamic aldehyde monomers as discussed above. The hesperidin monomer interacts with ascorbic acid ones in one hand and with cinnamic aldehyd monomer on other hand; each case is characterized by hydrogen bond $\mathrm{O}-\mathrm{H} \cdots \mathrm{O}$ interactions of 1.846 and $1.943 \AA$ for the former and 1.797 and $2.857 \AA$ for the latter.
It is interesting to note that the mixture of hesperidin, ascorbic acid and cinnamic aldehyd does not show interactions; thus, it is not possible to get a product composed of these three components.

\section{Energy decomposition analysis and bonding}

In order to give further explanation to the different intermolecular interactions occurred in the six cases (1)-(6), the Morokuma-Ziegler [32, 33, 44, 45] energy decomposition analysis (EDA) was applied. The total bonding energy between molecules is formulated as the sum of three components, the Pauli repulsion $\left(\Delta E_{\text {Pauli }}\right)$, the electrostatic interaction energy ( $\left.\Delta E_{\text {Elstat }}\right)$ and the orbital interaction energy ( $\Delta E_{\text {orb }}$ ) for the B3LYP method (The results are given in Table 1): $\Delta E_{\text {int }}=\Delta E_{\text {pauli }}+\Delta E_{\text {elstat }}+\Delta E_{\text {orb }}$.

The $\Delta E_{\text {int }}(1)$ (without BSSE correction [36]) and $\Delta E_{\text {int }}$ (2) (with BSSE correction [36]) interaction energies between the interacting molecules are negatives putting emphasis on stabilizing effects due to the hydrogen bonding interactions. It appears from Table 1 that the total interaction energies have different order of magnitude depending on the interacting molecule types. As can see in Table 1, the total interaction energies strengthen in the presence of the ascorbic acid, where the interactions are more strengths in the case (1) followed by

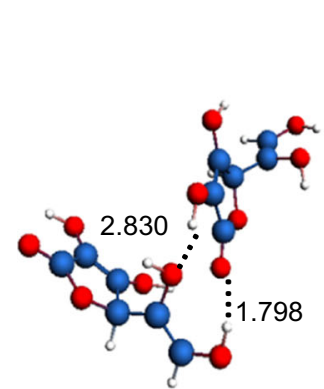

(a)

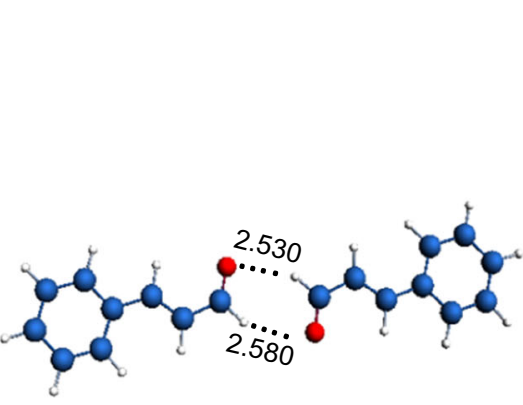

(b)

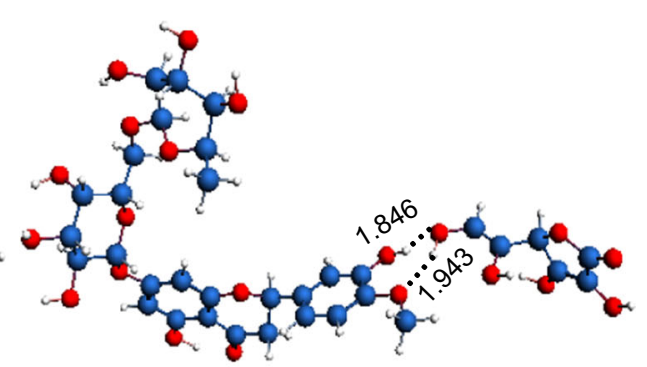

(c)

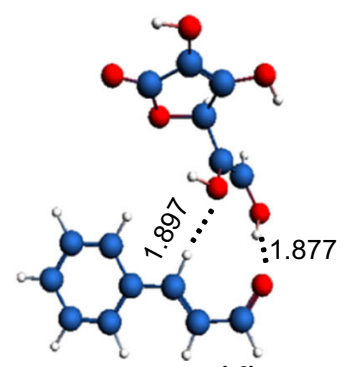

(d)

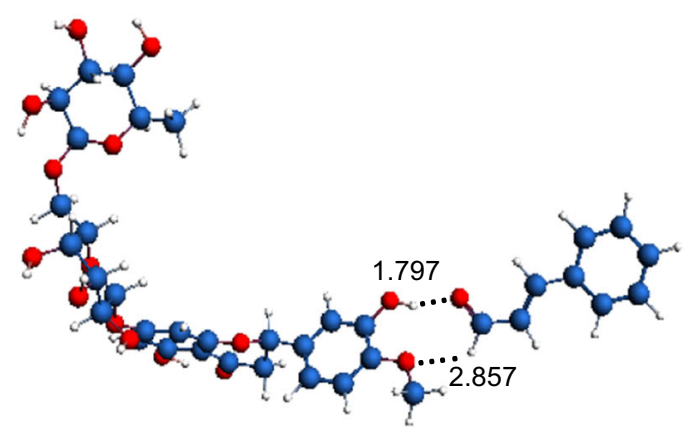

(e)

(d) and hesperidin + cinnamic aldehyd (e). The given values correspond to the $\mathrm{H} \cdots \mathrm{O}$ distances of the hydrogen bonds

Fig. 3 Lowest optimized structures obtained by intermolecular interactions between ascorbic acid dimer (a), cinnamic aldehyd dimer (b), hesperidin + ascorbic acid (c), cinnamic aldehyd + ascorbic acid 
Table 1 Total interaction energies without and with BSSE correction $\Delta E_{\text {int }}(1)$ and $\Delta E_{\text {int }}(2)$, respectively, and its components ( $\mathrm{kcal} / \mathrm{mol}$ ) obtained by energy decomposition analysis (EDA) for dimers (1), (2) and (3) and mixture complexes (4), (5) and (6)

\begin{tabular}{lllllll}
\hline & $\begin{array}{l}\text { Cinnamic } \\
\text { aldehyde } \\
(2)\end{array}$ & $\begin{array}{l}\text { Ascorbic } \\
\text { acid (1) }\end{array}$ & $\begin{array}{l}\text { Hesperidin } \\
(3)\end{array}$ & $\begin{array}{l}\text { Cinnamic } \\
\text { aldehyde }+ \\
\text { ascorbic acid (5) }\end{array}$ & $\begin{array}{l}\text { Cinnamic } \\
\text { aldehyde }+ \\
\text { hesperidin (6) }\end{array}$ & $\begin{array}{l}\text { Ascorbic acid } \\
+ \text { hesperidin } \\
(4)\end{array}$ \\
\hline$\Delta E_{\text {int }}(1)$ & -2.37 & -9.70 & -5.10 & -7.16 & -5.97 & -5.42 \\
$\Delta E_{\text {int }}(2)$ & -2.23 & -8.90 & -4.95 & -6.60 & -5.47 & -4.30 \\
$\Delta E_{\text {pauli }}$ & 2.92 & 17.42 & 13.40 & 12.63 & 12.31 & 17.54 \\
$\Delta E_{\text {elstat }}$ & -3.84 & -17.07 & -12.20 & -11.96 & -11.30 & -14.47 \\
$\Delta E_{\text {orb }}$ & -1.45 & -10.05 & -6.30 & -7.83 & -6.99 & -8.49 \\
\hline
\end{tabular}

(5). The total interaction energy $\Delta E_{\text {int }}(1)(-9.70 \mathrm{kcal} / \mathrm{mol})$ is the strongest reached for the ascorbic acid dimer, where the intermolecular interactions are relatively more significant as discussed above followed by those between cinnamic aldehyde and ascorbic acid $(-7.16 \mathrm{kcal} / \mathrm{mol})$. The total interaction energies between the hesperidin and cinnamic aldehyde on one hand and between hesperidin and ascorbic acid on other hand are moderate of -5.97 and $-5.42 \mathrm{kcal} / \mathrm{mol}$, respectively. The smaller absolute value is the weakest total bonding energy $(-2.37 \mathrm{kcal} /$ mol) that corresponds to the interactions between cinnamic aldehyde molecules. According to the stabilization energy gathered in Table 1, the hydrogen bonds can be classified as weak for (2) and moderate or even strong for (1), (3), (4), (5) and (6) as presented in previous work [43]. The total interaction energies arising from intermolecular interactions without BSSE correction obey the following (Table 1): $(1)>(5)>(6)>(4)>(3)>(2)$, while this classification undergoes a change giving the interactions in (3) $(-4.95 \mathrm{kcal} / \mathrm{mol})$ slightly strong than those encountered in (4) $(-4.30 \mathrm{kcal} / \mathrm{mol})$. It is important to note that the BSSE correction [38] contributes weakly in the interaction energies ranging from to 0.14 (cinnamic aldehyde dimer)) to $1.30 \mathrm{kcal} / \mathrm{mol}$ (ascorbic acid + hesperidin). The destabilization of the interaction energies $\Delta E_{\text {int }}(2)$ taking into account the BSSE correction is due to the weak stabilization of monomers than dimers.

The attractive interaction relative to the electrostatic and orbital components is overbalanced by the positive Pauli repulsive interaction due to the repulsion of oxygen lone pairs (two-orbital, four-electron repulsions of the $\mathrm{O} \cdots \mathrm{O}$ separation in the range 3.651-3.903 $\AA$ ) with considerable amounts (ranging from 12.31 to $17.54 \mathrm{kcal} / \mathrm{mol}$ ) except for the cinnamic aldehyd $(2.92 \mathrm{kcal} / \mathrm{mol})$. The positive Pauli repulsive energies (Table 1) account for the destabilizing interactions between the occupied orbitals and are dependable for any steric repulsion.

As can see in Table 1, the total attractive energies $\left(\Delta E_{\text {elstat }}+\Delta E_{\text {orb }}\right)$ are predominantly electrostatic in character in relationship with amounts ranging from 60 to $73 \%$, although charge transfer also contributes to their strength. The interactions are more ionic than covalently in all cases, particularly for the cinnamic aldehyd where the electrostatic interactions attain $73 \%$ against relatively weak covalent contribution of $27 \%$, while the orbital contribution attains a considerable participation in the case (5) giving rise to a marked covalent character of $40 \%$.

\section{Molecular properties}

The parameters gathered in Table 2 are calculated to provide further information about prediction of biological activities for dimers (1), (2) and (3) and mixture complexes (4), (5) and (6).. The HOMO and LUMO values and their energy gap represent the chemical activity and kinetic stability of the molecules [46, 47].

In order to predict the biological activities, the HOMOLUMO gap, the chemical hardness [17, 18], chemical potential and global electrophilicity [19] have been investigated (see Table 2) for the molecules (1), (2) and (3) and the mixtures (4), (5) and (6). The HOMO-LUMO gap is among the useful parameters evaluating the stability and chemical reaction of the molecules. For all cases (1)-(6) large HOMOLUMO gaps are computed, where a system with a large energy gap is chemically less reactive, therefore, could be more stable. The plots of Fig. 4 show the HOMO and LUMO variations. One can see the LUMOs' energies lowering and the HOMOs' energies raising when going from (1) to (6) leading to good interactions as frontier molecular orbitals.

When the cinnamic aldehyd is mixed with hesperidin or ascorbic acid, noticeable variations occurred. Indeed, the HOMO energies enhance in both cases and the LUMO ones decrease highlighting best reactivity as well illustrated in Fig. 4.

The chemical hardness $\eta=1 / 2$ (IP $-\mathrm{EA}$ ) is an electronic quantity characterizing the relative stability of molecule and is a measure of the resistance of a chemical entity to change the number of electrons $[17,18]$. The chemical potential is given by the formula $\mu=(I P+E A) / 2$, while the electrophilicity index $\omega=\mu^{2} / 2 \eta$. It is known that the electrophilicity index $(\omega)$ quantifies the electrophilic nature of the entire molecule [19]. It has been used to predict toxicity [48] and biological activity [49]. 
Table 2 The molecular properties (HOMO and LUMO energies, HOMO-LUMO gap, ionization potential, electron affinity, chemical potential and electrophilicity in $\mathrm{eV}$ and the dipolar moment in Debye) calculated for dimers (1), (2) and (3) and the mixture complexes (4), (5) and (6) obtained by B3LYP functional

\begin{tabular}{lcccccc}
\hline Molecular property & $\begin{array}{l}\text { Ascorbic } \\
\text { acid (1) }\end{array}$ & $\begin{array}{l}\text { Cinnamic } \\
\text { aldehyde (2) }\end{array}$ & Hesperidin (3) & $\begin{array}{l}\text { Ascorbic acid + } \\
\text { hesperidin (4) }\end{array}$ & $\begin{array}{l}\text { Cinnamic aldehyde + } \\
\text { ascorbic acid (5) }\end{array}$ & $\begin{array}{l}\text { Cinnamic aldehyde + } \\
\text { hesperidin (6) }\end{array}$ \\
\hline$E_{\text {HOMO }}$ & -6.590 & -6.716 & -6.544 & -6.420 & -6.465 & -5.829 \\
$E_{\text {LUMO }}$ & -1.636 & -2.494 & -2.102 & -2.037 & -2.943 & -3.140 \\
HOMO-LUMO gap & 4.964 & 4.222 & 4.442 & 4.383 & 3.522 & 2.689 \\
Ionization potential & 6.590 & 6.716 & 5.05 & 6.420 & 6.465 & 5.829 \\
Electron affinity $(\mathrm{EA})$ & 1.636 & 2.494 & 2.09 & 2.037 & 2.943 & 3.140 \\
Chemical hardness $(\eta)$ & 2.477 & 2.111 & 1.480 & 2.188 & 1.761 & 1.344 \\
Chemical potential $(\mu)$ & -4.113 & -4.605 & -3.570 & -4.288 & -4.704 & -4.484 \\
Electrophilicity $(\omega)$ & 3.414 & 5.023 & 4.310 & 4.091 & 6.283 & 7.480 \\
Dipolar moment & 4.426 & 5.09 & 2.95 & 4.830 & 5.95 & 13.20 \\
\hline
\end{tabular}

As can be seen from the Table 2, the biological activities could enhance according to the diminution of chemical hardness values.

It is worthnoting that the highest global electrophilicity corresponds to the mixture of cinnamic aldehyd with hesperidin $(7.48 \mathrm{eV})$ followed by that of ascorbic acid with cinnamic aldehyd $(6.28 \mathrm{eV})$, which match well with the smallest chemical hardness of $1.34 \mathrm{eV}$ for the former and $1.76 \mathrm{eV}$ for the latter matching well with the highest absolute value of chemical potential $(4.61 \mathrm{eV})$. These findings are comparable to those for our recent work [50] and suggest high biological activities, because the electrophilicity value enhances with enhancement chemical and biological activities. However, the mixture of ascorbic acid and hesperidin does not enhance significantly the electropholicity predicting the maintenance of biological activities like as before the mixing.

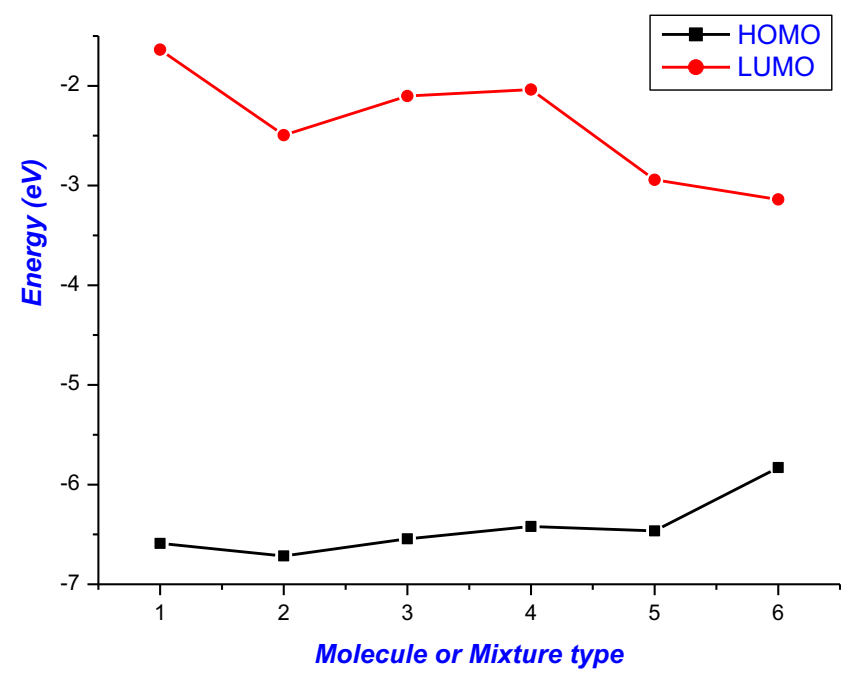

Fig. 4 HOMO and LUMO energies (eV) variation for ascorbic acid (1), cinnamic aldehyd (2), hesperidin (3) dimers and mixture complexes for ascorbic acid + hesperidin (4), cinnamic aldehyd + ascorbic acid (5) and cinnamic aldehyd + hesperidin (6)
Accordingly, the highest values of electrophilicity $(\omega)$ match up with the lowest values of chemical hardness $(\eta)$ and the highest absolute values of chemical potential $(\mu)$ and reciprocally.

Furthermore, the dipole moments (Table 2) for the studied molecules and mixtures obey the following order: $(3)<((1)$ $<(4)<(2)<(5)<(6)$. The dipole moment of the mixture $(6)$ suggests that it is the more polarized one, while molecule (3) and (1) are the less polarized allowing the electron transfer from the donor to the acceptor. The mixture (6) has the highest polarity, so it dissolves in blood more than the others followed the mixture (5). It is worth noting that the dipole moment for dimers (1), (2) and (3) are not equal to zero due to the dissymmetry between the two monomers, because the geometry optimizations are carried out on all structures without symmetry constraints (Fig. 5).

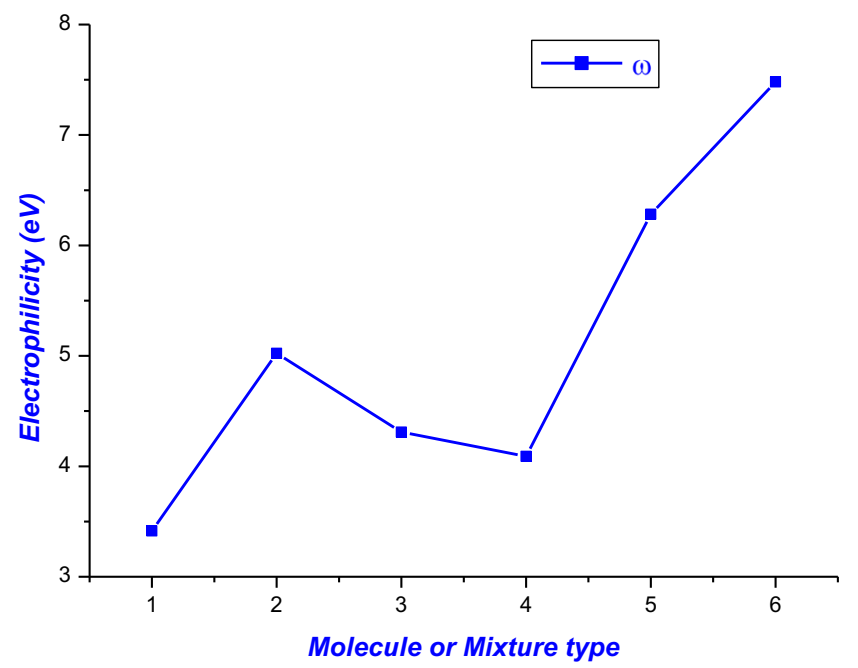

Fig. 5 Electrophilicity's (eV) variation for ascorbic acid (1), cinnamic aldehyd (2), hesperidin (3) dimers and mixture complexes for ascorbic acid + hesperidin (4), cinnamic aldehyd + ascorbic acid (5) and cinnamic aldehyd + hesperidin (6) 


\section{Conclusion}

This paper reports a theoretical investigation based on optimizations of molecule contained in cinnamon and citrus, particularly cinnamic aldehyd, ascorbic acid and hesperidin and of the intermolecular interactions of their mixtures. Density functional calculations are used to evaluate the HOMO-LUMO gaps and the energy decomposition. The main interactions are hydrogen bonds that occurred between HOMOs and LUMOs. The source of the hydrogen bonds stabilization is mainly electrostatic and has remarkable contributions from a charge transfer from the acceptor to the donor. As a result, the hydrogen bond has a partial covalent bond character between $\mathrm{H}$ and $\mathrm{O}$. The $\mathrm{O}-\mathrm{H} \cdots \mathrm{O}$ bond angle tends to be linear in most cases.

The $\mathrm{H}^{\cdots} \mathrm{O}$ separation is in the range $1.70-2.80 \AA$, which suggests stable intermolecular hydrogen bonds, and there is a slightly bent $\mathrm{O}-\mathrm{H} \cdots \mathrm{O}$ moiety corresponding to weak and moderate hydrogen bonding, in agreement with the total bonding energies. From the attractive energy amounts, the intermolecular interactions are more ionic than covalent according to the electrostatic and orbital contributions, respectively.

The destabilization energies relative to the Pauli repulsion occurring through intermolecular interactions are due to repulsions of the facing electron pairs of the oxygen atoms in all cases. From the calculated reactivity indices, the ascorbic acid and hespridin display a nucleophilic character against an electrophilic character of cinnamic aldehyd.

Our DFT calculations showed for the mixtures of cinnamic aldehyde + ascorbic acid on one hand and the cinnamic aldehyd + the hesperidin on another hand a considerable enhancement of the electrophilicity, a remarkable decrease of chemical hardness and an augmentation of absolute values of chemical potentials compared with those of cinnamic aldehyde. In fact, these mixtures predict an important improvement of the biological activities, particularly the reinforcement of the human body's immunity and the antiviral activity. The ascorbic acid + hesperidin enhances the dissolution of cinnamon in blood with the regard to the augmentation of the polarity of mixtures (5) and (6). Furthermore, the mixture (6) of hesperidin + cinnamon could be an excellent blood thinner and could be proposed as domestic safe treatment against viruses and particularly COVID-19.

Funding information The authors received financial support from the Algerian MESRS (Ministère de l'Enseignement Supérieur et de la Recherche Scientifique) and DGRSDT (Direction Générale de la Recherche Scientifique et du Développement Technologique).

\section{Compliance with ethical standards}

Conflict of interest The author declares that he has no conflict of interest.

\section{References}

1. Molania T, Moghadamnia A, Pouramir M, Aghel S, Moslemi D, Ghassemi L, Motallebnejad M (2012) The effect of Cinnamaldehyde on mucositis and salivary antioxidant capacity in gamma-irradiated rats (a preliminary study). J Pharm Sci 20:89-93

2. Subash Babu P, Prabuseenivasan S, Ignacimuthu S (2007) Cinnamaldehyde - a potential antidiabetic agent. Phytomedicine 14:15-22

3. Wei Z, Yan-cheng XU, Fang-jian G, Ye Ming-li ML (2008) Antidiabetic effects of cinnamaldehyde and berberine and their impacts on retinol-binding protein 4 expression in rats with type 2 diabetes mellitus. Chin Med J 121:2124-2128

4. Hyeon K, Hee-Juhn P, Hyun JJ, Jong WC, Kyu-SC H, Joohun L, Kyung T (2003) Cinnamaldehyde induces apoptosis by ROSmediated mitochondrial permeability transition in human promyelocytic leukemia HL-60 cells. Cancer Lett 196:143-152

5. Han DC, Lee MY, Shin KD, Jeon SB, Kim JM, Son KH, Kim HC, Kim HM, Kwon BM (2004) 2'-Benzoyloxycinnamaldehyde induces apoptosis in human carcinoma via reactive oxygen species. J Biol Chem 279:6911-6920

6. Chao LK, Hua KF, Hsu HY, Cheng SS, Lin IF, Chen CJ, Chen ST, Chang ST (2008) Cinnamaldehyde inhibits pro-inflammatory cytokines secretion from monocytes/macrophages through suppression of intracellular signalling. Food Chem Toxicol 46:220-231

7. Tung YT, Chua MT, Wang SY, Chang ST (2008) Antiinflammation activities of essential oil and its constituents from indigenous cinnamon (Cinnamomum osmophloeum) twigs. Bioresour Technol 99:3908-3913

8. Shin DS, Kim JH, Lee SK, Han DC, Son KH, Kim HM, Cheon HG, Kim KR, Sung ND, Lee SJ, Kang SK, Kwon BM (2006) Synthesis and biological evaluation of dimeric cinnamaldehydes as potent antitumor agents. Bioorg Med Chem 14:2498-2506

9. Fatima M, Sahar N, Zaidi S, Amraiz D, Afzal F (2016) In vitro antiviral activity of Cinnamomum cassia and its nanoparticles against H7N3 influenza a virus. J Microbiol Biotechnol 26:151159

10. Parak WJ, Gerion D, Pellegrino T, Zanchet D, Micheel C, Williams SC, Boudreau CA, Le Gros MA, Larabell CA, Alivisatos AP (2003) Biological applications of colloidal nanocrystals. Nanotechnology 14:15-27

11. Pauling L (1971) The significance of the evidence about ascorbic acid and the common cold. Proc Natl Acad Sci U S A 68:2678

12. Colunga Biancatelli RML, Berrill M, Marik PE (2020) The antiviral properties of vitamin C. Expert Rev Anti-Infect Ther 18:99-101

13. Kim GN, Yoo WS, Park MH, Chung JK, Han YS, Chung IY, Seo SW, Yoo JM, Kim SJ (2018) Clinical features of herpes simplex keratitis in a Korean tertiary referral center: efficacy of Oral antiviral and ascorbic acid on recurrence. Korean J Opthalmol 32:353-360

14. Ahmad ST, Arjumand W, Nafees S, Seth A, Ali N, Rashid S, Sultana S (2012) Hesperidin alleviates acetaminophen induced toxicity in Wistar rats by abrogation of oxidative stress, apoptosis and inflammation. Toxicol Lett 208:149-161

15. Akiyama S, Katsumata S, Suzuki K, Ishimi Y, Wu J, Uehara M (2010) Dietary hesperidin exerts hypoglycemic and hypolipidemic effects in streptozotocin-induced marginal type 1 diabetic rats. J Clin Biochem Nutr 46:87-92

16. Akiyama S, Katsumata S, Suzuki K, Ishimi Y, Uehara M (2009) Hypoglycemic and hypolipidemic effects of hesperidin andcyclodextrin-clathrated hesperetin in Goto-Kakizaki rats with type 2 diabetes. Biosci Biotechnol Biochem 73:2779-2782

17. Pearson RG (1987) Recent advances in the concept of hard and soft acids and bases. J Chem Educ 64:561

18. Parr R, Yang W (1989) Density-functional theory of atoms and molecules. Oxford Univ, Press, New York 
19. Parr RG, Szentpaly LV, Liu S (1999) Electrophilicity index. J Am Chem Soc 121:1922-1924

20. ADF2016.01, SCM, Theoretical Chemistry. Vrije Universiteit, Amsterdam

21. Baerends EJ, Ellis DE, Ros P (1973) Self-consistent molecular Hartree-fock-Slater calculations I. The computational procedure. Chem Phys 2:41-51

22. te Velde G, Baerends EJ (1992) Numerical integration for polyatomic systems. J Comput Phys 99:84-98

23. Fonseca Guerra C, Snijders JG, te Velde G, Baerends EJ (1998) Towards an order-N DFT method. Theor Chem Accounts 99:391403

24. Bickelhaupt FM, Baerends EJ (2000) Kohn-Sham density functional theory: predicting and understanding chemistry. Rev Comput Chem 15:1-86

25. te Velde G, Bickelhaupt FM, Fonseca Guerra C, van Gisbergen SJA, Baerends EJ, Snijders JG, Ziegler T (2001) Chemistry with ADF. J Comput Chem 22:931

26. Becke AD (1993) Becke's three parameter hybrid method using the LYP correlation functional. J Chem Phys 98:5648-5652

27. Lee C, Yang W, Parr RG (1988) Development of the Colle-Salvetti correlation-energy formula into a functional of the electron density. Phys Rev B Condens Matter 37:785

28. Vosko SD, Wilk L, Nusair M (1990) Accurate spin-dependent electron liquid correlation energies for local spin density calculations: a critical analysis. Can J Chem 58:1200-1211

29. Versluis L, Ziegler T (1988) The determination of molecular structures by density functional theory. The evaluation of analytical energy gradients by numerical integration. J Chem Phys 88:322328

30. Fan L, Ziegler T (1992) Application of density functional theory to infrared absorption intensity calculations on main group molecules. J Chem Phys 96:9005-9012

31. Fan L, Ziegler T (1992) Application of density functional theory to infrared absorption intensity calculations on transition-metal carbonyls. J Chem Phys 96:6937-6941

32. Ziegler T, Rauk A (1979) A theoretical study of the ethylene-metal bond in complexes between copper (1+), silver (1+), gold (1+), platinum ( 0 ) or platinum (2+) and ethylene, based on the HartreeFock-Slater transition-state method. Inorg Chem 18:1558-1565

33. Bickelhaupt FM, Baerends EJ (eds) (2000) vol 15. Wiley, New York, p 1-86

34. Weinhold F, Landis CR (2005) Valency and bonding: a natural bond order donor acceptor perspective. Cambridge University Press, Cambridge

35. Glendening ED, Badenhoop JK, Reed AE, Carpenter JE, Bohmann JA, Morales P, Karafiloglou CM, Landis CR, Weinhold F (2018) NBO 7.0.; Theoretical Chemistry Institute, University of Wisconsin, Madison

36. Boys SF, Bernardi F (1970) The calculation of small molecular interactions by the differences of separate total energies. Some procedures with reduced errors. Mol Phys 19:553-566
37. Merzoug M, Zouchoune B (2014) Coordination diversity of the phenazine ligand in binuclear transition metal sandwich complexes: theoretical investigation. J Organomet Chem 770:69-78

38. Korichi H, Zouchoune F, Zendaoui SM, Zouchoune B, Saillard JY (2010) The coordination chemistry of azulene: a comprehensive DFT investigation. Organometallics. 29:1693-1706

39. Zendaoui SM, Zouchoune B (2013) Molecular properties and electronic structure of phenazine ligand in binuclear molybdenum and manganese metal complexes: a density functional theory study. Polyhedron 51:123-131

40. Bouchakri N, Benmachiche A, Zouchoune B (2011) Bonding analysis and electronic structure of transition metalebenzoquinoline complexes: a theoretical study. Polyhedron 30:2644-2653

41. Zouchoune B, Merzoug M, Bensalem N (2019). Struct Chem. https://doi.org/10.1007/s11224-019-01322-Z

42. Farah S, Ababsa S, Benhamada N, Zouchoune B (2010) Theoretical investigation of the coordination of dibenzazepine to transition-metal complexes. Polyhedron 29:2722-2730

43. Grabowski SJ (2006) Theoretical studies of strong hydrogen bonds. Annu Rep Prog Chem 102:131-165

44. Morokuma KJ (1971) Molecular orbital studies of hydrogen bonds. III. $\mathrm{C}=\mathrm{O} \cdots \mathrm{H}-\mathrm{O}$ hydrogen bond in $\mathrm{H}_{2} \mathrm{CO} \cdots \mathrm{H}_{2} \mathrm{O}$ and $\mathrm{H}_{2} \mathrm{CO} \cdots$ $2 \mathrm{H}_{2} \mathrm{O}$. Chem Phys 55:1236-1244

45. Ziegler T, Rauk A (1979) Carbon monoxide, carbon monosulfide, molecular nitrogen, phosphorus trifluoride, and methyl isocyanide as sigma donors and pi acceptors. A theoretical study by the Hartree-Fock-Slater transition-state method. Inorg Chem 18: 1755-1959

46. Li XH, Liu XR, Zhang XZ (2011) Molecular structure and vibrational spectra of three substituted 4-thioflavones by density functional theory and ab initio Hartree-Fock calculations. Spectrochim Acta A Mol Biomol Spectrosc 78:528-536

47. Padmaja L, Ravikumar C, Sajan D, Hubert Joe I, Jayakumar V, Pettit G, Faurskov Nielsen O (2009) Density functional study on the structural conformations and intramolecular charge transfer from the vibrational spectra of the anticancer drug combretastatinA2. J Raman Spectrosc 40:419-428

48. Roy DR, Sarkar U, ChattarajPK MA, Padmanabhan J, Parthasarathi R, Subramanian V, Damme SV, Bultinck P (2006) Analyzing toxicity through electrophilicity. Mol Divers 10:119-131

49. Roy DR, Pal N, Mitra A, Bultinck P, Parthasarathi R, Subramanian V, Chattaraj PK (2007) An atom counting strategy towards analyzing the biological activity of sex hormones. Eur J Med Chem 42: 1365-1369

50. Saouli S, Belkacemia A, Zouchoune B, Sid A, Zendaoui SM, Bensouici C, Bendeif E (2020) Synthesis, spectroscopic characterization, crystal structure, DFT studies and biological activities of new hydrazone derivative: $1-(2,5-$ bis ((E)-4isopropylbenzylidene)cyclopentylidene)-2-(2,4-dinitrophenyl) hydrazine. J Mol Struct 1213:128203

Publisher's note Springer Nature remains neutral with regard to jurisdictional claims in published maps and institutional affiliations. 